\title{
Metodologias ativas aplicadas a Educação Profissional e Tecnológica
}

\author{
Active methodologies applied to Professional and Technological Education \\ Metodologías activas aplicadas a la Educación Profesional y Tecnológica
}

Recebido: 10/01/2022 | Revisado: 14/01/2022 | Aceito: 17/01/2022 | Publicado: 19/01/2022

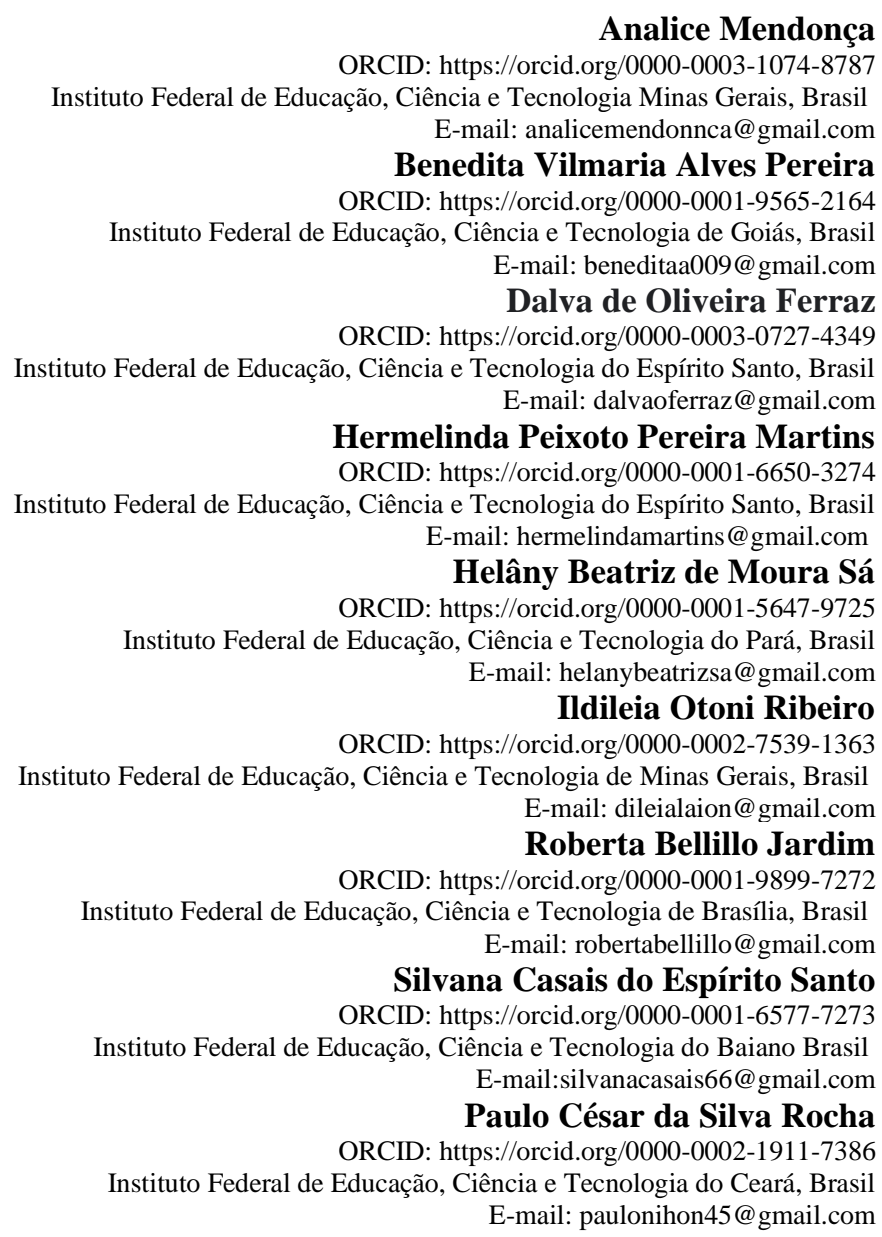

\section{Resumo}

O objeto de estudo desta pesquisa são as metodologias ativas na perspectiva da Educação Profissional e Tecnológica, que é uma abordagem sobre a evolução da identidade educativa do trabalho diante do sentido mercadológico adquirido historicamente através do processo de desenvolvimento capitalista, assim como sobre a educação e suas transformações ao longo da história, analisando suas mudanças e destacando o desvelamento quanto ao projeto educacional brasileiro atual. Esse estudo é de natureza qualitativa, como uma pesquisa que surge diante da impossibilidade de compreender, através de dados numéricos, fenômenos ligados à intuição e subjetividade, portanto, não necessitando de uma estrutura numérica para analisá-lo, contudo, que produz uma enorme quantidade de dados narrativos. Assim, a nossa análise será feita a partir da investigação de dados encontrados nos documentos selecionados. Tendo em vista que as bases conceituais da educação profissional e tecnológica defendem uma educação humana integral, com perspectivas da unilateralidade, é importante compreender o sujeito como um todo, ou seja, um sujeito que não seja formado apenas para o mercado de trabalho, mas que tenha possibilidade de uma articulação entre educação e trabalho.

Palavras-chave: Metodologia ativas; Educação profissional e tecnológica; Ensino.

\section{Abstract}

The object of study of this research are active methodologies from the perspective of Professional and Technological Education, which is an approach to the evolution of the educational identity of work in light of the market sense historically acquired through the process of capitalist development, as well as on education and its transformations throughout history, analyzing its changes and highlighting the unveiling of the current Brazilian educational project. 
This study is qualitative in nature, as a research that arises from the impossibility of understanding, through numerical data, phenomena linked to intuition and subjectivity, therefore, it does not need a numerical structure to analyze it, however, which produces a huge amount of narrative data. Thus, our analysis will be based on the investigation of data found in the selected documents. Considering that the conceptual bases of professional and technological education defend a comprehensive human education, with perspectives of unilateralism, it is important to understand the subject as a whole, that is, a subject who is not trained only for the labor market, but who have the possibility of a link between education and work.

Keywords: Active methodology; Professional and technological education; Teaching.

\section{Resumen}

El objeto de estudio de esta investigación son las metodologías activas desde la perspectiva de la Educación Profesional y Tecnológica, que es un acercamiento a la evolución de la identidad educativa del trabajo a la luz del sentido de mercado adquirido históricamente a través del proceso de desarrollo capitalista, así como sobre la educación y sus transformaciones a lo largo de la historia, analizando sus cambios y destacando la develación del actual proyecto educativo brasileño. Este estudio tiene un carácter cualitativo, como una investigación que surge de la imposibilidad de comprender, a través de datos numéricos, fenómenos ligados a la intuición y la subjetividad, por lo tanto, no necesita de una estructura numérica para analizarlo, sin embargo, lo que produce una enorme cantidad de datos narrativos. Por lo tanto, nuestro análisis se basará en la investigación de los datos encontrados en los documentos seleccionados. Considerando que las bases conceptuales de la educación profesional y tecnológica defienden una educación humana integral, con perspectivas de unilateralismo, es importante comprender al sujeto como un todo, es decir, un sujeto que no está capacitado solo para el mercado laboral, sino que tiene la posibilidad de un vínculo entre educación y trabajo.

Palabras clave: Metodología activa; Educación profesional y tecnológica; Enseñando.

\section{Introdução}

O objeto de estudo desta pesquisa são as metodologias ativas na perspectiva da Educação Profissional e Tecnológica, que é uma abordagem sobre a evolução da identidade educativa do trabalho diante do sentido mercadológico adquirido historicamente através do processo de desenvolvimento capitalista, assim como sobre a educação e suas transformações ao longo da história, analisando suas mudanças e destacando o desvelamento quanto ao projeto educacional brasileiro atual.

As metodologias ativas são as práticas de ensino e aprendizagem que utilizam experiências reais ou simuladas com o objetivo de solucionar uma situação específica Berbel (2011)

Quando estratégias de metodologias ativas de aprendizagem são aplicadas em sala de aula, a principal tarefa do professor é orientar os alunos através desse processo de aprendizagem, ajudando-os a descobrir por si mesmos o conhecimento, usando para isso as ferramentas que melhor se adequem ao caráter e personalidade de cada aluno (Canaleta et al., 2014).

No método ativo, é realizado pelos alunos, um estudo prévio do material indicado pelo professor e debatido em sala de aula com os colegas, apresentando os conceitos (Araújo \& Mazur, 2013).

Nessa direção, parece-nos que a formação deve ser estruturada com base numa estratégia que, entre outras, permita a modificação das atitudes dos professores face ao "potencial pedagógico" dos novos recursos disponíveis, como destacam Costa e Viseu (2018) através da tomada de consciência da importância, utilidade e benefícios que esses materiais, utilizados como ferramentas de aprendizagem, podem trazer ao processo de ensinar e de aprender.

Ao que se ver, as metodologias ativas, não se referem a um modismo, elas existem há muito tempo. Freire já defendia em suas teorias essas metodologias que partissem da realidade do aluno e que desenvolvessem sua autonomia. Evidente que Freire não deu esse nome de metodologias ativas, mas sua teoria e sua prática de alfabetização enfatiza o protagonismo do aluno, as quais as metodologias ativas tem esse objetivo.

O pensamento freiriano corrobora com as metodologias ativas, pois a vê como uma concepção educativa que estimula processos construtivos de ação-reflexão-ação (Freire, 2006). Assim, não só o professor conduzirá o processo de ensino, como também os próprios alunos.

No mesmo viés do ensino e da aprendizagem, Paulo Freire aponta que ensinar exige apreensão da realidade, pesquisa e esperança de mudanças. E é importante que o professor se veja como educador e como sujeito do processo de formação, assim 
como o aluno, pois não há docência sem discência. O processo é dialético, já que o ser humano é histórico e inacabado e a ação transformadora se dá na interação (Freire, 2002).

Nesse processo, educador e educando se renovam em função das suas posições, interações e das suas práticas, "Educador e educando, os dois seres criadores libertam-se mutuamente para chegarem a ser, ambos, criadores de novas realidades", Freire (1979), desse modo, nas práticas educativas da EPT, o educador para com o educando na ação pedagógica, será eficiente o emprego da teoria, quando essa se direcionar a transformar a prática, e diante dessa influência, acontecendo mudança na prática, simultaneamente acontecerá na teoria e assim acontece a práxis.

Para Santos et a.l (2020), o impacto causado, as mudanças de comportamento das pessoas, a necessidade de informação quase instantânea, a "enxurrada" de estímulos que as novas tecnologias, impulsionadas pela internet, proporcionam ao indivíduo fez com que a escola e seus métodos de ensino ficassem "obsoletos" e "desinteressantes".

Segundo Chimentão (2009), a formação continuada é um dos motores para "a transformação do professor, pois é através do estudo, da pesquisa, da reflexão, do constante contato com novas concepções, proporcionado pelos programas de formação continuada, que é possível a mudança. Pois, fica mais difícil o professor mudar seu modo de pensar, o fazer pedagógico, se ele não tiver a oportunidade de vivenciar novas experiências, novas pesquisas, novas formas de ver e pensar a escola.

Assim, sugere-se, entre outras medidas, que a análise de cada produto seja feita em torno da reflexão com base em critérios predominantemente pedagógicos como, por exemplo, a pertinência, relevância e adequação aos objetivos curriculares e as aprendizagens de carácter transversal para que o currículo remete.

Ainda nessa direção, superando perspectivas simplistas como a educação bancária devidamente caracterizada por Paulo Freire (2018), atos de fazer e ensinar pressupõe empregos de metodologias que preparem os indivíduos para tais ações, o que adquire caráter mais dificultoso diante de realidades enfrentadas no cotidiano de sala de aula, em que alunos apresentam défices de formação/aprendizagem, bem como estão mais adaptados a contextos educacionais eminentemente reprodutivistas.

Diversos referenciais teóricos apontam a relevância da mediação pedagógica e das metodologias ativas para a educação. Por isso, faz-se necessário que tais assuntos também sejam discutidos e inseridos na Educação Profissional e Tecnológica ofertada na modalidade a distância, bem como façam parte da formação dos professores, pois é a atuação deles que contribuirá para a interação e a aprendizagem satisfatórias.

\section{Metodologia}

Este estudo é de natureza qualitativa, entendida por Figueiredo (2009, p. 96) como uma pesquisa que surge diante da impossibilidade de compreender, através de dados numéricos, fenômenos ligados à intuição e subjetividade, portanto, não necessitando de uma estrutura numérica para analisá-lo, contudo, que produz uma enorme quantidade de dados narrativos. Assim, a nossa análise será feita a partir da investigação de dados encontrados nos documentos selecionados.

Como destacado por Minayo (2002) a abordagem qualitativa estabelece relações entre indivíduos e é proposta como “[...] tarefa central das ciências sociais a compreensão da realidade humana vivida socialmente” (Minayo, 2002, p. 23). O estudo apresentado teve como intenção, proporcionar aos educadores(as) entendimento e busca pela compreensão metodológica abarcados nesta proposta.

Este trabalho é fruto da leitura crítica do referencial teórico previamente selecionado a partir de levantamento bibliográfico. De acordo com Gil (2008, p. 50), "a pesquisa bibliográfica é desenvolvida a partir de material já elaborado, constituído principalmente de livros e artigos científicos". Sendo assim, foi realizada uma revisão narrativa, sendo selecionados artigos dos últimos 10 anos escolhidos de forma aleatória sobre a temática em questão.

Nesse sentido, o presente artigo dialoga com autores que discutem uma perspectiva das metodologias ativas sobre diferentes pontos de vista, assim como essa articulação entre as metodologias ativas e a Educação Profissional e Tecnológica. 
Segundo Gil (2008), a utilização dessa abordagem permite o aprofundamento das questões relacionadas ao fenômeno estudado e as suas relações, sendo permitida pela valorização de um maior contato direto com a situação em estudo, buscandose o que era comum, mas permanecendo, entretanto, aberta para perceber a individualidade e os significados múltiplos.

\section{Resultados e Discussão}

A definição de metodologias ativas está relacionada à postura mais ativa dos estudantes no processo de ensino e aprendizagem. O uso de métodos ativos de ensino não é uma novidade. Conforme Mattar (2017), o filósofo Sócrates (469-339 a.C) buscava ensinar as pessoas provocando a participação delas por meio de questionamentos.

O filósofo denominou esse processo de maiêutica - a arte de fazer nascer as ideias. Assim como Sócrates, outros filósofos, psicólogos, educadores e pesquisadores de diferentes concepções pedagógicas defenderam e defendem, como princípio educacional, a construção do conhecimento ao invés da mera transmissão de informações.

Como destaca Moran (2018), metodologia ativa é definida como estratégias de ensino centradas na participação efetiva dos estudantes na construção do processo de aprendizagem, de forma flexível, interligada e híbrida. Essa construção pode ser individual, grupal e tutorial - com a orientação de um mediador experiente. Nessa direção, Peçanha e Toledo (2016) compreendem como prática pedagógica alicerçada no princípio da autonomia, pressuposto da educação contemporânea que espera um estudante capaz de autogerenciar ou autogovernar seu processo de formação.

Seguindo esse pensamento, Silva (2018) destaca que uma metodologia ativa reconhece e potencializa a participação ativa e colaborativa de todos os envolvidos e, desse modo, mobiliza processos para alterar percursos e garantir resultados. Cavalcanti e Filatro (2018) apontam que, em linhas gerais, as metodologias ativas se ancoram em uma visão mais humanista, menos tecnicista da educação, e são inspiradas por teóricos cujas teses foram erguidas em contraposição a modelos tradicionais vigentes.

A utilização das metodologias ativas deve promover uma recriação do conhecimento de alcance bastante ousado. Educadores e educandos que utilizem tais metodologias devem estar dispostos a uma profunda revisão de suas próprias concepções, dentro de uma práxis emancipatória.

O maior desafio dessa metodologia é fazer com que tiremos o foco sobre o indivíduo e comecemos a olhar a educação como um todo, permitindo a compreensão de aspectos cognitivos, efetivos, socioeconômicos, políticos e culturais, e fazendo, assim, uma prática pedagógica socialmente contextualizada.

Já para Sobral e Campos (2012), a metodologia ativa é um método de concepção educativa que instiga o processo de ensino-aprendizagem crítico-reflexivo, no qual o aluno se compromete e participa de sua aprendizagem. A técnica propõe a elaboração de situações que promovam a aproximação crítica do discente com a realidade, fazendo com que tenha a reflexão sobre problemas que causam curiosidades e desafios e, assim, disponibilizando recursos para pesquisar problemas e soluções.

Para Freitas et al (2020), deste modo, a metodologia ativa traz responsabilidade ao próprio discente, que precisará desenvolver autonomia, criticidade e reflexão, bases que cercam esse método de estudo. Tudo isso é corroborado pela estimulação por experiências sejam elas reais ou simuladas em vários contextos.

Welter (2020) ressalta que nesse contexto, tendo em vista que as pessoas estão cada vez mais conectadas, fazem-se necessárias, mudanças na educação, ou ainda, nos métodos de ensino-aprendizagem. E as teorias sobre metodologias ativas, atualmente reinterpretadas, fornecem subsídios para uma prática mais dinâmica, centrada na criatividade, interação e autonomia do aluno. Ou seja, as metodologias ativas de aprendizagem colocam o aluno em atividades interativas com outros estudantes, em que aprendem e se desenvolvem de modo colaborativo.

Freitas et al (2020) destacam que o processo de problematizar vai além de somente de apresentar situações problemas, mas também na exposição de fatos, discussão de meios, sustentação de resoluções e vários outros intermédios que permeiam 
esse processo. Entretanto, algumas concepções que estão enraizadas no método tradicional devem ser mudadas para contemplação destes processos.

Neste sentido, Silva e Fernandes (2020), uma das possibilidades para diversificação de estratégias de ensino, na sala de aula, é o uso do lúdico e de metodologias ativas como ferramentas para despertar o interesse dos alunos pela leitura. Assim, a prática educativa foi desenvolvida, visando levar para a sala de aula novos paradigmas de leitura, para que o aluno seja capaz de perceber, por meio da sua experiência, que ler pode ser algo prazeroso e significativo.

Luckesi (2011) exprime que, no ensino tradicional, os conteúdos, os procedimentos didáticos e a relação professoraluno não têm nenhuma conexão com o cotidiano do aluno, muito menos com as realidades sociais, sendo a ênfase na memorização e repetição de conceitos e fórmulas visando a disciplinar a mente do aluno. Vasconcelos (2015) assinala que este tipo de ensino tem raízes na concepção clássica de Educação (Antiguidade) e é a tradição oral uma das mais antigas modalidades de transmissão cultural da humanidade.

Destaca que o professor não está interessado na dúvida do aluno, nem disposto a explicar de novo, mas pergunta se os alunos entenderam apenas pela formalidade do processo educativo, camuflando a pseudo-superação e pseudo-inovação que têm surgido na justaposição de discursos (aluno x professor ou vice-versa); tanto em suas falas quanto nas técnicas utilizadas pelo docente (pesquisa x exposição; exposição x dramatização).

Vasconcelos (2015) expressa, ainda, que iniciar uma aula perguntando aos alunos o que sabem sobre o assunto, depois de realizarem uma pesquisa prévia sobre ele, sem considerar suas opiniões, não significa desenvolver uma metodologia nova que o leve a problematizar, a relacionar com aquilo que conhece.

O princípio maior das metodologias ativas não é apenas fazer com que o aluno seja protagonista de sua aprendizagem e desenvolva autonomia. Segundo Berbel (2011), é necessário que o aluno seja capaz de inserir-se nas discussões, teorizar e trazer elementos novos, ainda não considerados na aula ou na perspectiva do docente. Há diferenças entre a intenção do professor e a sua concretização, haja vista as especificidades que podem suceder no decorrer de uma aula.

A semelhança entre metodologia dialética e as metodologias denominadas ativas pode ser verificada quando Vasconcelos (2015) discute três dimensões, eixos ou preocupações para o alcance da aprendizagem:

a mobilização para o conhecimento; a construção do conhecimento propriamente dito; e a elaboração e expressão da síntese do conhecimento, sendo a primeira dimensão papel do professor e as duas últimas papéis do aluno. Na primeira, mobilização para o conhecimento, há uma sensibilização do docente para criar uma situação que incite o discente à curiosidade, no desejo de se postar perante uma opinião, atribuindo significação ao objeto do conhecimento, de correlacionar o assunto com as experiências que o aluno possui (relação com necessidades), o que instiga o professor a elaborar um roteiro de trabalho e a formular questões que fomentem a criatividade daquele. (Vasconcelos, 2015, p.68)

Na perspectiva de Vasconcelos (2015), a mobilização visa a possibilitar o vínculo significativo inicial entre sujeito e objeto, provocar a necessidade, o recorte do objeto, sendo o trabalho do educador, a princípio, tornar o objeto em questão objeto do conhecimento para o aluno.

Na segunda dimensão, construção do conhecimento, deve-se possibilitar ao aluno o confronto entre sujeito e objeto, fazendo com que o discente apreenda a essência do objeto, sendo esta apreensão uma relação mais abrangente e complexa com o objeto.

O professor deve colaborar com o aluno na interpretação do objeto estudado. É possível que ocorram associações com outros conteúdos e representações, possibilitando ao aluno tirar as próprias conclusões, sendo esta dimensão fundamental para compreender a dimensão posterior A terceira, a elaboração e expressão da síntese do conhecimento, é relativa à sistematização dos conhecimentos que vêm sendo adquiridos, bem como sua expressão. 
Vasconcelos (2015) enfatiza que não é uma sequência rígida das dimensões, mas uma orientação para a formulação do conhecimento em sala de aula, devendo haver relações entre cada uma delas. O processo de construção do conhecimento passa pelos processos de síncrese (visão caótica, global, fragmentada do objeto), análise (debruçamento teórico sobre o objeto, estabelecendo relações entre o todo e as partes) e síntese (apropriação do objeto).

$\mathrm{O}$ autor defende também o argumento de que a metodologia dialética, ao seguir esses passos, não deve ser pensada em termos de uma aula apenas, mas para um conjunto de aulas ou para a totalidade de um curso.

A relevância concedida ao professor na primeira dimensão reflete-se na capacidade que ele deve possuir para elaborar um planejamento condizente em relação aos conteúdos a serem trabalhados e à realidade do aluno.

Esta articulação entre ambos deve desencadear um confronto entre o que o aluno já traz para a instituição formadora com os conhecimentos discutidos e sensibilizados pelo professor, necessitando deste a reinvenção de suas metodologias de ensino, caso contrário, haverá mecanização de um comportamento condicionado.

Referencia-se que as metodologias ativas são aquelas capazes de suscitar maior participação dos alunos, engajamento destes nas ações desenvolvidas e interesse intrínseco em sua realização; que os discentes sejam capazes de protagonizar e gerenciar sua aprendizagem, sendo a autonomia elemento de grande destaque.

Quando se diz que nessas metodologias o foco é o discente, não se está excluindo a participação conjunta do professor, mas, para que aquele seja posto no centro dos processos de ensino e aprendizagem, urge a necessidade deste gerenciar meios para que esta centralidade aconteça.

\section{Considerações Finais}

Tendo em vista que as bases conceituais da educação profissional e tecnológica defendem uma educação humana integral, com perspectivas da unilateralidade, é importante compreender o sujeito como um todo, ou seja, um sujeito que não seja formado apenas para o mercado de trabalho, mas que tenha possibilidade de uma articulação entre educação e trabalho.

Seguindo os princípios neoliberais, a educação baseada nesta lógica, teremos uma educação unilateral, formando indivíduos fragmentados, incompletos no sentido da formação. Isso significa, que são necessárias estratégias que formem o indivíduo em suas amplas dimensões, e as metodologias ativas abrem margem para esta discussão, sempre ressaltando a importância de rever a intencionalidade dessas atividades. Ressalta-se que a atividade não é o fim, mas o meio.

Nessa direção, defende-se a partir do apanhado das leituras realizadas nesta pesquisa, que as metodologias ativas podem e devem fazer parte de um currículo integrado, sempre buscando articular as melhores práticas e atividades que possam proporcionar para o estudante um conhecimento amplo, e que possa proporcionar uma formação autônoma, crítica, e que dê condições desse sujeito discutir, explicar e entender o seu próprio contexto e o contexto do mundo a partir dos conhecimentos mediados, para além dos conteúdos técnicos.

\section{Referências}

Araujo, R. M. \& Frigotto, G. (2015) Práticas pedagógicas e ensino integrado. Revista educação em questão, Natal, 52 (38), 61-80.

Bacich, L \& Moran, J. (2018.). Metodologias ativas para uma educação inovadora: uma abordagem teórico-prática. Ed. Penso

Berbel, N. A. N. (2011) As metodologias ativas e a promoção da autonomia de estudantes. Semina: Ciências Sociais e Humanas, Londrina, 32 (1), 25-40

Canaleta, X. Et al. (2014). Master in teacher training: A real implementation of active learning. Computers in human behavior, 31, 651-658

Cavalcanti, C. \& Filatro, A. (2018). Metodologias inov-ativas na educação presencial, a distância e corporativa. 1. Ed. Saraiva.

Chimentão, L. K. (2009) O significado da formação continuada docente. In: Congresso Norte Paranaenses De Educação Física Escolar. 4, 2009 , Londrina.

Costa, F. A. \& Viseu, S.(2008) Formação-ação-reflexão: um modelo de preparação de professores para a integração curricular das TIC. In: Fernando Costa; Helena Peralta; Sofia Viseu (Eds.). As TIC na educação em Portugal: concepções e práticas. Ed. Porto Editora, 2008. 238-258. 
Freitas, F. R. N.; Souza, A. T. da S., Carvalho, N. A. de, \& Pedrosa, J. I. dos S. (2020). Metodologias ativas de ensino nos cursos de medicina: uma revisão integrativa. Research, Society and Development, 9(7), e151973922. https://doi.org/10.33448/rsd-v9i7.3922

Figueiredo, N. M. A. (2011) Método e metodologia na pesquisa científica - 3. ed. Editora Yendis .

Freire, P. Conscientização: teoria e prática da libertação: uma introdução ao pensamento de Paulo Freire. [tradução de Kátia de Mello e silva; revisão técnica de Benedito Eliseu Leite Cintra]. Cortez \& Moraes. São Paulo. SP, 1979.

Luckesi, C. C. (2011) Filosofia da educação. 3 ed. Cortez.

Lima, M. M; Silva, D. M.; Tahim, A. P. \& Santos, V. S. (2017) As metodologias ativas: avaliação acerca da sua adoção no ensino superior. In: Congresso Internacional Em Avaliação Educacional Avaliação E Seus Espaços: Desafios E Reflexões, 7., Fortaleza, 9-11 nov. 2016. Anais... Fortaleza: UFC, 2017. p. 1116-1134.L

Mattar. J. (2017) Metodologias ativas: para a educação presencial, blended e a distância. 1. ed. Artesanato Educacional.

Minayo, M. C. S. (1998) O desafio do conhecimento: pesquisa qualitativa em saúde. 5. ed.: Hucitec-Abrasco.

Moran, J. M. (2018) Metodologias ativas para uma aprendizagem mais profunda. In: BACICH, Lilian.; Moran, José. (Org.). Metodologias ativas para uma educação inovadora: uma abordagem teórico-prática. Ed. Penso.

Peçanha, M. P. \& Toledo, M. T. (2016)Metodologias Ativas de Ensino e Aprendizagem: ABE E ABP. In: SCHLIEMANN, Ana Laura; ANTONIO Jorge Luiz (Orgs). Metodologias ativas na Uniso: formando cidadãos participativos. Ed. Eduniso.

Santos, M. E. K. L. dos, Luz, J. O. C. da, \& Martins, P. B. (2020). A utilização de metodologias ativas no processo de ensino/aprendizagem de matemática alinhadas a Base Nacional Comum Curricular. Research, Society and Development, 9(5), e103952989. https://doi.org/10.33448/rsd-v9i5.2989

Silva, B. (2018) O Design Thinking para ações colaborativas e participativas na escola. In: INSTITUTO CRESCER. Inovações na prática pedagógica: formação continuada de professores para competências de ensino no século XXI. Bárbara Szuparits (Org.) Crescer em Rede: Edição Especial - Metodologias Ativas.

Silva, K. de L., \& Fernandes, J. C. da C. (2020). Metodologias Ativas e o Lúdico: possibilidades de práticas de leitura em salas de aula. Research, Society and Development, 9(7), e122973694. https://doi.org/10.33448/rsd-v9i7.3694

Vasconcelos, C. S. (2015) Construção do conhecimento em sala de aula. 20 ed. Libertad.

Ventura, P. P. B. (2019) Indicadores de metodologias ativas com suporte das tecnologias digitais: estudo com docentes do Instituto Federal de Educação, Ciência e Tecnologia do Ceará. 2019. 195f. - Tese (Doutorado) - Universidade Federal do Ceará, Programa de Pós-graduação em Educação, Fortaleza (CE)

Welter, R. B. \& Foletto, D. da S., \& Bortoluzzi, V. I. (2020). Metodologias ativas: uma possibilidade para o multiletramento dos estudantes. Research, Society and Development, 9(1), e106911664. https://doi.org/10.33448/rsd-v9i1.1664 